\title{
Long-Term Corrosion Protection of a Cupro-Nickel Alloy Due to Graphene Coating
}

\author{
Abhishek Tiwari 1,2,* (D) and R. K. Singh Raman 1,3 \\ 1 Department of Mechanical and Aerospace Engineering, Monash University, Clayton, Victoria 3800, \\ Australia; raman.singh@monash.edu \\ 2 Department of Mechanical Engineering, Bansal Institute of Research and Technology, Kokta, Anand Nagar, \\ Bhopal 462021, India \\ 3 Department of Chemical Engineering, Monash University, Clayton, Victoria 3800, Australia \\ * Correspondence: abhishektiwariiitr@gmail.com; Tel.: +91-952-255-7320
}

Academic Editor: Alessandro Lavacchi

Received: 20 September 2017; Accepted: 13 November 2017; Published: 23 November 2017

\begin{abstract}
This study demonstrates the corrosion resistance of a $\mathrm{Cu}-\mathrm{Ni}$ alloy coated with a multi-layer graphene. This is one of the first demonstrations of long-term corrosion resistance due to graphene coating, which is crucial since earlier studies have suggested graphene-coated copper to be considerably inferior to bare copper in terms of corrosion during long-term exposure to a corrosive environment. The inferior corrosion resistance of graphene-coated copper arises due to defects and poor surface coverage by graphene. Since it is prohibitively difficult to develop defect-free graphene on metals at a commercially feasible scale, this study investigated the hypothesis for an alternative approach, i.e., to develop multi-layer graphene with a reasonable assumption that the areas of defects/poor coverage of a layer will be masked by the subsequent over-layer(s). This study has validated this hypothesis. Electrochemical investigations have demonstrated multi-layer graphene to improve the corrosion resistance of a $\mathrm{Cu}-\mathrm{Ni}$ alloy by an order of magnitude. However, the most striking finding of this study is that the improvement in corrosion resistance due to the multi-layer graphene coating sustained the entire duration of a long-term test $(\sim 350 \mathrm{~h})$.
\end{abstract}

Keywords: Cu-Ni alloy; graphene; EIS; Raman spectroscopy; chemical vapour deposition; corrosion

\section{Introduction}

Corrosion and its mitigation are an ongoing and costly problem [1]. Therefore, successful application of a novel approach to mitigation of corrosion has attractive socioeconomic implications. An ultra-thin barrier coating of graphene is a disruptive approach to corrosion resistance. The great interest in graphene as an effective coating for corrosion resistance arose due to highly relevant properties of graphene, such as remarkable chemical inertness (even to aggressive HF) [2], impermeability (even to tiny He atom) [3], and high toughness [4]. Politano and Chiarello [5] demonstrated that the Poisson's ratio and 2D Young's modulus of graphene were 0.19 and $342 \mathrm{~N} / \mathrm{m}$, respectively, in the case of both flat and corrugated graphene, showing the usefulness of graphene for electromechanical devices and carbon-fibre reinforcements. There have been a few studies showing water adsorption on graphene [6,7]; however, this does not contradict the idea that graphene is chemically inert, for adsorption is not a chemical reaction. The growth of graphene on bimetallic surfaces such as $\mathrm{Pt}_{3} \mathrm{Ni}(111)$ is another area of recent interest since graphene provides enhanced catalytic activity to such surfaces [8]. Furthermore, graphene-based membranes have attracted interest for desalination as well as liquid and gas separation [9]. Corrosion resistance of an ultra-thin graphene-coated copper was found to be superior to bare copper by up to two orders of magnitude in an aggressive chloride solution (similar to seawater) [10]. Chen et al. [11] were the first to investigate the ability of graphene coating to provide corrosion resistance. 
They grew a monolayer of graphene on top of $\mathrm{Cu}$ and a $\mathrm{Cu} / \mathrm{Ni}$ alloy using an established $\mathrm{CVD}$ process. They demonstrated that graphene coating could effectively protect the surface of metals during exposure to air at $200{ }^{\circ} \mathrm{C}$ for $4 \mathrm{~h}$. They also subjected a penny (95\% Cu, 5\% Zn, minted 1962-1982), one half of which was CVD graphene-coated, to a highly oxidising solution of $30 \% \mathrm{H}_{2} \mathrm{O}_{2}$, and found that the surface of the graphene-coated half of the penny suffered no visible change in appearance, whereas the uncoated half got badly tarnished due to oxidation by $\mathrm{H}_{2} \mathrm{O}_{2}$, confirming graphene to be an effective corrosion-resistant coating. However, different studies on graphene as a corrosion-resistant coating $[10,12-15]$ suggest a great variability in the extent of corrosion resistance of copper due to graphene coating. Singh Raman et al. [10] reported that the graphene coating improved the corrosion resistance of copper by nearly two orders of magnitude, Prasai et al. [12] found the improvement to be only an order of magnitude, and Kirkland et al. [13] reported the improvement to be insignificant. In fact, Schriver et al. [14] and Zhou et al. [15] have categorically reported the corrosion resistance of the graphene-coated copper to be considerably inferior to that of bare copper during long-term exposure to ambient air. Such remarkable variabilities in the corrosion resistance of CVD graphene-coated copper have been attributed to the defects and discontinuities in coating that are commonly present in CVD graphene, such as poor surface coverage, cracks, graphene domain boundaries, and wrinkles [16].

Zhou et al. [15] demonstrated the corrosion resistance of graphene-coated copper to be worse than that of bare copper during a six-month exposure to air. However, Kalita et al. [17] showed that graphene coating provided oxidation resistance to copper when exposed for short durations $(1 \mathrm{~h})$ at $150{ }^{\circ} \mathrm{C}$ in air. Schriver et al. [14] investigated the durability of oxidation resistance of copper due to graphene coating at 185 and $250^{\circ} \mathrm{C}$. They found graphene to provide corrosion resistance during initial/short exposure but the graphene-coated copper showed inferior corrosion resistance during prolonged exposure. However, a close scrutiny of the results reported in their paper suggests that extensive oxidation during prolonged exposure was limited to locations where graphene was defective/disrupted, whereas the areas where graphene was reasonably defect-free did not suffer oxidation.

The great variability in the extent of corrosion resistance of copper due to graphene coating in the reported studies [1-5] indicates the need for a full surface coverage of graphene for durable corrosion resistance. Wlasny et al. [16] suggested that cracks in the graphene provide windows for nanoscale corrosion and showed such instances of localised corrosion. Hsieh et al. [18], who also reported that nanometre-sized defects in CVD graphene deteriorate corrosion protection, also undertook masking of these defects by atomic layer deposition (ALD) of aluminium oxide on graphene-coated copper, thereby considerably enhancing the corrosion resistance.

$\mathrm{Cu}-\mathrm{Ni}$ alloys find application in various industries, e.g., coin minting, armaments, desalination, and marine engineering. They are also extensively used in the chemical, petrochemical, and electrical industries due to the specific properties of copper and nickel [19]. They also find uses in piping, heat exchangers and condensers for seawater systems, marine hardware, propellers, and crankshafts and hulls of premium tugboats because of their high corrosion resistance in seawater. When $\mathrm{Cu}-\mathrm{Ni}$ alloys are used for ships operating in polluted seawater, they often corrode much faster than expected-800 mpy (mils per year) — due to sulphide contamination [20-23].

There are a few studies of the aqueous corrosion of graphene-coated $\mathrm{Cu}$ and $\mathrm{Ni}[10,12,13]$. However, there has been no study on the corrosion behaviour of multilayer graphene-coated $\mathrm{Cu} / \mathrm{Ni}$ alloys in aqueous environment, which may be critical since multilayer graphene can provide better surface coverage, which can potentially improve corrosion resistance.

On the basis of the preceding description of the findings on graphene as a corrosion barrier, we hypothesized that a more effective surface coverage and corrosion resistance may be attained with multilayer graphene. Hence, an increase in the number of graphene layers may play a role in improving corrosion resistance due to a decrease in wettability.

In this study, we experimentally demonstrate that a multilayer graphene coating provides durable corrosion resistance to a $\mathrm{Cu}-\mathrm{Ni}$ alloy. This is a systematic electrochemical investigation on the aqueous corrosion resistance of the $\mathrm{Cu}-\mathrm{Ni}$ alloy in a $0.1 \mathrm{M} \mathrm{NaCl}$ solution. 


\section{Methods}

\subsection{Test Materials}

The chemical composition of the Cu-Ni (75/25) alloy used in this study, as shown in Table 1 , was determined by Spectrometer Services Pty Ltd. (Coburg, Australia).

The electrolyte used in the electrochemical tests was $0.1 \mathrm{M} \mathrm{NaCl}$ solution.

Table 1. Chemical composition of the $\mathrm{Cu}-\mathrm{Ni}(75 / 25)$ alloy.

\begin{tabular}{cccc}
\hline Element & wt $\%$ & Element & wt \% \\
\hline $\mathrm{Cu}$ & Bal. & $\mathrm{Mn}$ & 0.31 \\
$\mathrm{Si}$ & 0.01 & $\mathrm{Sn}$ & $<0.01$ \\
$\mathrm{Fe}$ & $<0.01$ & $\mathrm{Al}$ & $<0.01$ \\
$\mathrm{Zn}$ & 0.03 & $\mathrm{P}$ & $<0.01$ \\
$\mathrm{~Pb}$ & $<0.01$ & $\mathrm{As}$ & $<0.01$ \\
$\mathrm{Cr}$ & $<0.01$ & $\mathrm{Sb}$ & $<0.01$ \\
$\mathrm{Ni}$ & 24.3 & & \\
\hline
\end{tabular}

\subsection{Chemical Vapour Deposition (CVD) of Graphene on a Cu-Ni Alloy}

Discs of the Cu-Ni alloy (thickness $\sim 0.8 \mathrm{~mm}$ and diameter $12.5 \mathrm{~mm}$ ) were polished with $\mathrm{SiC}$ paper up to 2500 grit and cleaned with acetone and deionised water. The cleaned discs were placed in the middle zone of the quartz tube of a furnace for CVD of graphene. The quartz tube was first pumped down to a pressure of 70 mTorr, and then a gas mixture of $85 \%$ Ar and $15 \% \mathrm{H}_{2}$ was introduced at a pressure of 8-9 Torr and a flow rate of $400 \mathrm{sccm}$. The reducing atmosphere of $\mathrm{H}_{2}$ is employed for avoiding oxidation of the $\mathrm{Cu}-\mathrm{Ni}$ alloy at high temperatures as well as for the reduction of the native oxide layer on the $\mathrm{Cu}-\mathrm{Ni}$ alloy, thereby providing a pristine alloy surface for graphene deposition. The furnace was heated to $1000{ }^{\circ} \mathrm{C}$ at a heating rate of $30{ }^{\circ} \mathrm{C} / \mathrm{min}$, while maintaining the reducing atmosphere of $\mathrm{Ar} / \mathrm{H}_{2}$ flow. The $\mathrm{Cu}-\mathrm{Ni}$ coupons were annealed for $4 \mathrm{~min}$ at $1000{ }^{\circ} \mathrm{C}$ under a reducing atmosphere, and then the $\mathrm{Ar} / \mathrm{H}_{2}$ flow was replaced with a n-hexane vapour that was passed at $4.4 \mathrm{sccm}$ and 1 Torr for $6 \mathrm{~min}$. Then, the $\mathrm{Cu}-\mathrm{Ni}$ coupons were cooled under the flow of $\mathrm{Ar} / \mathrm{H}_{2}$ flow at $400 \mathrm{sccm}$ and at a pressure of 8-9 Torr.

The growth conditions of graphene films on a Cu-Ni alloy have been listed in Table 2.

Table 2. Growth conditions for CVD growth of graphene on a Cu-Ni alloy.

\begin{tabular}{cccc}
\hline $\begin{array}{c}\text { Base Pressure/Initial } \\
\text { Vacuum }\end{array}$ & $\begin{array}{c}\text { Ar/ } \mathbf{H}_{2} \text { Pressure in Quartz Tube } \\
\text { during Heating and Annealing }\end{array}$ & $\begin{array}{c}\text { Flow Rate of Ar/ } \mathbf{H}_{2} \text { both } \\
\text { during Annealing and Cooling }\end{array}$ & Annealing Time \\
\hline $70 \mathrm{mTorr}$ & 8-9 Torr & $400 \mathrm{sccm}$ & $4 \mathrm{~min}$ \\
\hline $\begin{array}{c}\text { Reaction Temperature } \\
\text { and Heating Rate }\end{array}$ & Duration of N-Hexane Flow & $\begin{array}{c}\text { N-Hexane Flow Rate } \\
\text { and Pressure }\end{array}$ & $\begin{array}{c}\mathrm{Ar} / \mathrm{H}_{2} \text { Pressure in Quartz } \\
\text { Tube during Cooling }\end{array}$ \\
\hline $1000^{\circ} \mathrm{C}$ and $30^{\circ} \mathrm{C} / \mathrm{min}$ & $6 \mathrm{~min}$ & $4.4 \mathrm{sccm}$ and 1 Torr & $8-9$ Torr \\
\hline
\end{tabular}

\subsection{Characterisation of Graphene}

The coated samples, developed as described in the preceding section, were characterised using Raman spectroscopy and optical microscopy to search for the presence of graphene and describe the physical properties (morphology and defects).

\subsubsection{Raman Spectroscopy}

The Cu-Ni samples subjected to CVD treatment were characterised using a Renishaw micro-Raman Spectrometer (Model inVia Renishaw plc, Wotton-under-Edge, UK) that uses a HeNe (632.8 nm) laser operating at $100 \%$ power. The Raman spectrometer was also equipped with a microscope and the laser light was coupled with an objective lens of $50 \times$, which was used for exciting the sample as well as 
collecting the Raman signals. Extended scans (10 s) were performed at a spectral range between the Raman shifts of 150-3200 $\mathrm{cm}^{-1}$ with a laser spot size of $1 \mu \mathrm{m}$. Prior to each Raman run, the system was wavenumber-calibrated with the known Raman peak of a solid silicon standard centred at $520.5 \mathrm{~cm}^{-1}$ (see Supplementary Materials Figure S1). Subtraction of the baseline using cubic spline interpolation was done in order to eliminate unwanted background noise and facilitate data analysis.

\subsubsection{Optical Microscopy}

The optical micrographs of bare and graphene-coated $\mathrm{Cu}-\mathrm{Ni}$ alloys were obtained using an Olympus BX 51 optical microscope (Model BX51TRF, Olympus Corporation, Tokyo, Japan). Optical microscopy enabled observation of the surface coverage of graphene coating on the alloy sample.

\subsection{Electrochemical Characterisation}

Potentiodynamic polarization and electrochemical impedance spectroscopy (EIS) were employed for qualitative and quantitative characterisation of corrosion kinetics of graphene-coated and uncoated samples in $0.1 \mathrm{M} \mathrm{NaCl}$, using a Princeton Applied Research (PAR) potentiostat (Model 2273, Princeton Applied Research, Advanced Measurement Technology, Inc., Oak Ridge, TN, USA). All the electrochemical experiments were performed in a conventional three-electrode electrochemical cell (specimens with an exposed area of $0.785 \mathrm{~cm}^{2}$ acted as the working electrode, platinum mesh as a counter electrode, and saturated calomel electrode as the reference electrode). $E_{c o r r}$ vs. time plots were generated after immersion in $0.1 \mathrm{M} \mathrm{NaCl}$ for $1 \mathrm{~h}$, to ascertain the stabilized open circuit potential (OCP).

\subsubsection{Potentiodynamic Polarisation}

The cathodic and anodic plots were generated by sweeping the potential on either side of the OCP at a scan rate of $0.1667 \mathrm{mV} / \mathrm{s}$ (ASTM F2129-04 [24]) for graphene-coated and uncoated metal samples. The sweeping was carried out over the potential range of $-300 /+300 \mathrm{mV}$ for graphene-coated and uncoated $\mathrm{Cu}-\mathrm{Ni}$ alloy samples.

\subsubsection{Electrochemical Impedance Spectroscopy (EIS)}

Electrochemical impedance spectroscopy (EIS) was performed on the graphene-coated and bare samples in a $0.1 \mathrm{M} \mathrm{NaCl}$ solution using PAR potentiostat and an electrochemical cell with three electrodes (the cell was described earlier). First, the $E_{\text {corr }}$ vs. time plots were generated after immersion in $0.1 \mathrm{M} \mathrm{NaCl}$ for $1 \mathrm{~h}$, to ascertain the stabilized open circuit potential (OCP). When the fluctuation of OCP was limited to $<10 \mathrm{mV}$ for a period of $1000 \mathrm{~s}$, the condition was considered stable for the purpose of EIS experiments. EIS runs were carried out by applying a sinusoidal signal at $E_{\text {corr }}$ with a perturbation potential of $10 \mathrm{mV}$. Impedance response was measured over frequencies from $1 \mathrm{MHz}$ to $10 \mathrm{mHz}$, recording 10 points per decade of frequency using Powersuit software (version 2.58). These frequencies are chosen such that they reach the asymptotic limits, at which the imaginary impedance tends to zero at the lowest and highest frequencies of the employed frequency range.

Impedance analysis was carried out using PAR ZSimpWin (version 3.21) package for Windows for frequencies from $10,000 \mathrm{~Hz}$ to $0.1 \mathrm{~Hz}$, which prevented misinterpretation of any artefacts that may be present in the high-frequency region or the scatter in the low-frequency region.

A time-dependent EIS study was carried out after immersion of graphene-coated $\mathrm{Cu}-\mathrm{Ni}$ alloy in $0.1 \mathrm{M} \mathrm{NaCl}$ for different durations $(1,24,48,216,336 \mathrm{~h})$.

\section{Results and Discussions}

\subsection{Characterisation of Graphene}

Raman spectroscopy provides confirmatory information on whether the deposited layer is graphene. Ferrari et al. [25] determined for the first time, in 2006, the Raman signature for graphene. Graphene has two characteristic peaks, namely a G peak at $1580 \mathrm{~cm}^{-1}$ and a $2 \mathrm{D}$ peak at $2700 \mathrm{~cm}^{-1}$. 
Furthermore, Ni et al. [26] showed that the ratio of intensities of these peaks can determine the number of graphene layers. The number of graphene layers increases with the ratio of intensities $I_{G} / I_{2 D}$, and is roughly 0.36 for a single layer and $>1$ for bi- or multi-layer graphene [27].

The two signature Raman peaks of graphene are a $G$ peak at $1580 \mathrm{~cm}^{-1}$ and a $2 D$ peak at $2700 \mathrm{~cm}^{-1}$ (Ferrari et al. [25]). The ratio of intensities of the $G$ and $2 D$ peaks $\left(I_{G} / I_{2 D}\right)$, i.e., a measure of the number of graphene layers, is $\sim 0.5$ for a single layer in the case of the $\mathrm{Cu}-\mathrm{Ni}$ alloy and increases linearly with the number of layers. The $I_{G} / I_{2 D}$ ratio in a typical Raman spectrum in Figure 1 of the graphene films deposited in the present study is 3, which indicates 5-6 layers of graphene (the Raman spectrum in Figure 1 is representative of 5-6 such spectra (see Supplementary Materials Figure S2 for reproducibility)). The thickness of graphene coating in this study is around 1.675-2.01 nm (considering that there were 5-6 layers and the thickness of a single layer of graphene is $0.335 \mathrm{~nm}$ ). The D-peak at $1350 \mathrm{~cm}^{-1}$ signifies the extent of defects in graphene [28]. The relatively high intensity of the D peak in Figure 1 indicates that the graphene layers had considerable defects (such as vacancies and strained hexagonal/non-hexagonal (pentagon or heptagon) distortions that are reported to result in corrugation and twisting of layers [28]).

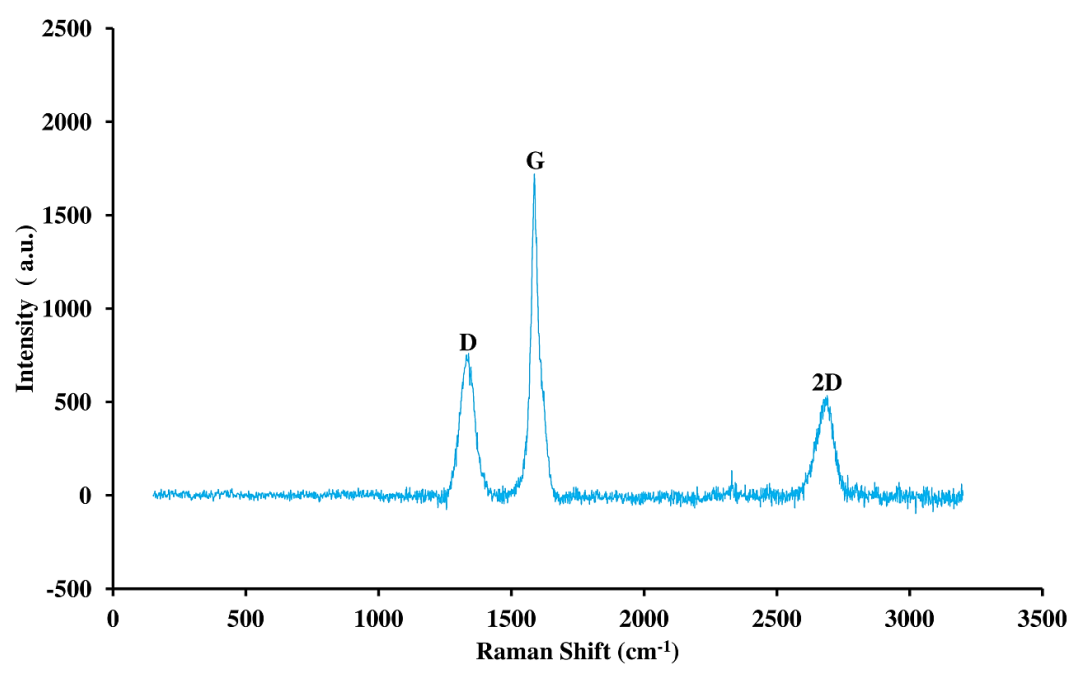

Figure 1. Raman spectrum of a graphene-coated $\mathrm{Cu}-\mathrm{Ni}$ alloy.

The optical micrographs of bare and graphene-coated $\mathrm{Cu}-\mathrm{Ni}$ alloy are shown in Figure 2.

Since the annealing time during the CVD process was only $4 \mathrm{~min}$, the extent of thermal etching of grain boundaries of $\mathrm{Cu}-\mathrm{Ni}$ alloy was limited and the thermally etched grain boundaries of the $\mathrm{Cu}-\mathrm{Ni}$ alloy are rarely seen (Figure $2 b$ ).

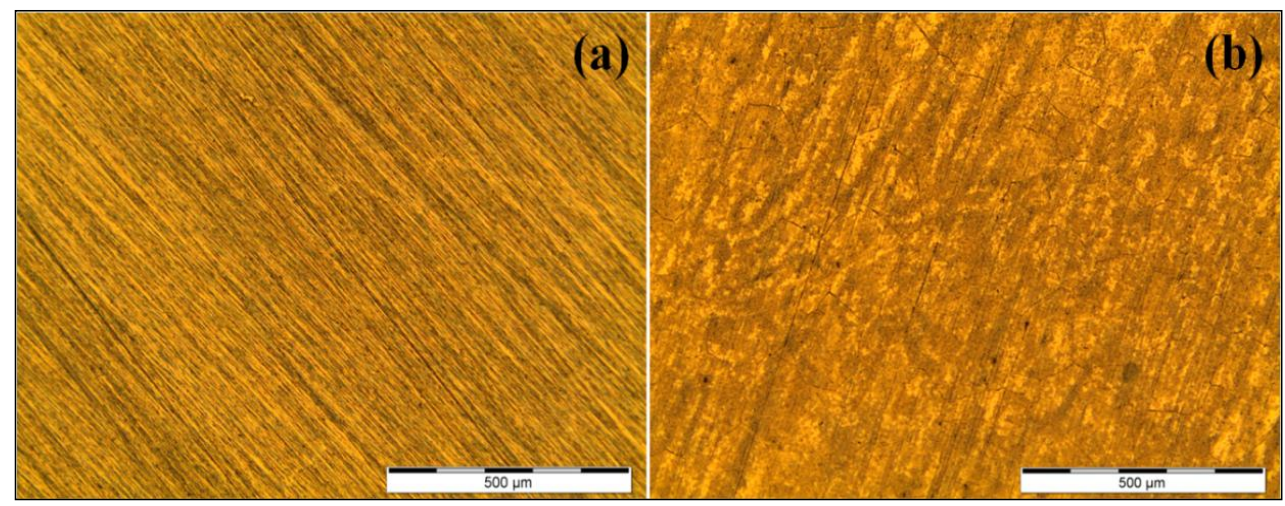

Figure 2. Optical micrographs of (a) bare and (b) graphene-coated Cu-Ni alloy. 


\subsection{Electrochemical Characterisation}

It is well established that $\mathrm{Cu}-\mathrm{Ni}$ alloys with sufficient $\mathrm{Cu}$ form a corrosion film composed of a thick, porous outer layer of $\mathrm{Cu}_{2}(\mathrm{OH})_{3} \mathrm{Cl}$ and a thin, adherent layer of $\mathrm{Cu}_{2} \mathrm{O}$ when exposed to aerated chloride solutions [21,22]. The outer layer offers little corrosion protection, while the inner layer provides corrosion protection [21]. During corrosion, the cathodic process of oxygen reduction occurs at the interface between the inner and outer corrosion film [21], as shown below. The anodic reaction of metal oxidation occurs at the interface between the oxide film and base metal [21]. While the above process of oxide formation is proceeding, a separate electrochemical process may be occurring simultaneously at the interface of the outer and inner corrosion product. This process is the dissolution of the oxide [21]. The cathodic process for the oxide dissolution is oxygen reduction, and the anodic process is oxidation of $\mathrm{Cu}^{+}$ions in the $\mathrm{Cu}_{2} \mathrm{O}$ film to $\mathrm{Cu}^{++}$ions in solution [21]. These $\mathrm{Cu}^{++}$ions, in turn, are responsible for the formation of the porous outer layer of $\mathrm{Cu}_{2}(\mathrm{OH})_{3} \mathrm{Cl}$ [21]. Therefore, the corrosion behaviour of $\mathrm{Cu}-\mathrm{Ni}$ alloys in aerated chloride solutions (e.g., seawater) is governed by the combined electrochemical process of metal oxidation and $\mathrm{Cu}_{2} \mathrm{O}$ dissolution [21]. The cathodic and anodic reactions for $\mathrm{Cu}-\mathrm{Ni}$ alloy are below:

Cathodic reaction:

$$
2 \mathrm{H}_{2} \mathrm{O}+\mathrm{O}_{2}+4 \mathrm{e}^{-} \rightarrow 4 \mathrm{OH}^{-} \quad \text { (oxygen reduction) }
$$

Anodic reaction:

$$
\begin{gathered}
\mathrm{Cu} \rightarrow \mathrm{Cu}^{+} \text {(oxide) }+\mathrm{e}^{-} \quad\left(\text { formation of } \mathrm{Cu}_{2} \mathrm{O} \text { film }\right) \\
\mathrm{Cu}^{+}(\text {oxide }) \rightarrow \mathrm{Cu}^{++}(\text {solution })+\mathrm{e}^{-}\left(\text {formation of } \mathrm{Cu}_{2}(\mathrm{OH})_{3} \mathrm{Cl} \text { film }\right)
\end{gathered}
$$

The potentiodynamic polarization of multilayer graphene-coated $\mathrm{Cu}-\mathrm{Ni}$ alloy and bare $\mathrm{Cu}-\mathrm{Ni}$ alloy after $1 \mathrm{~h}$ of immersion in $0.1 \mathrm{M} \mathrm{NaCl}$ suggested the anodic and cathodic current densities of multilayer graphene-coated $\mathrm{Cu}-\mathrm{Ni}$ alloy, respectively, to be nearly an order of magnitude lower than the uncoated $\mathrm{Cu}-\mathrm{Ni}$ alloy (Figure 3), indicating considerable improvement in the corrosion resistance of $\mathrm{Cu}-\mathrm{Ni}$ alloy due to the graphene coating. The corrosion potential $\left(E_{\text {corr }}\right)$ of the multilayer graphene-coated $\mathrm{Cu}-\mathrm{Ni}$ alloy was $60 \mathrm{mV}$ higher than that of the bare $\mathrm{Cu}-\mathrm{Ni}$ alloy (Figure 3). $E_{\text {corr }}$ is the measure of corrosion susceptibility, and, thus, a positive shift in $E_{\text {corr }}$ strongly indicates the corrosion protection ability of the graphene coating. The presence of noise in the cathodic region (absent in the anodic region) of the graphene-coated $\mathrm{Cu}-\mathrm{Ni}$ alloy is instrumental noise, unlike electrochemical noise. The electrochemical noise persists up to the pitting potential [29]. The instrumental noise was not observed in the case of the uncoated $\mathrm{Cu}-\mathrm{Ni}$ alloy because these measurements were in the coarser range of the current measurement. The vertical part of the uncoated $\mathrm{Cu}-\mathrm{Ni}$ alloy at a very negative potential is the diffusion-controlled cathodic reaction, which is a very common phenomenon for all tests (one would make a similar observation for graphene-coated $\mathrm{Cu}-\mathrm{Ni}$ alloy if one were to undertake a run from negative potential similar to that of the $\mathrm{Cu}-\mathrm{Ni}$ alloy).

Electrochemical impedance spectroscopy (EIS) provides a quantitative measurement of impedance (polarisation resistance) of bare and coated metals and alloys in response to a very small perturbation of the potential in an AC system. Because the perturbation potentials are very small (typically, $10 \mathrm{mV}$ ), EIS is a non-destructive technique for the detailed evaluation of the time-dependent electrochemical phenomena at interfaces, such as those that concern corrosion and coatings, viz., metal/electrolyte, coating/electrolyte, metal/coating interfaces. Quantitative determination of characteristic parameters such as capacitance, resistance, etc., involves a simulation of the experimental EIS data, employing an appropriate equivalent electrical circuit (EEC) based on hypothetical corrosion mechanism. The relative magnitudes of these interfacial resistances and capacitances provide insight into the corrosion protection provided by a film/coating and associated mechanism. The three main criteria to be fulfilled while choosing an appropriate EEC for corrosion process are: (i) a low chi-square value 
(typically of the order of $10^{-3}$ or lower); (ii) minimum total error and relative error in the calculation of individual parameters; and (iii) consistency with a corrosion mechanism [30]. The experimental EIS data are simulated for the chosen EEC using complex nonlinear least square (CNLS) fitting method, as described in [30].

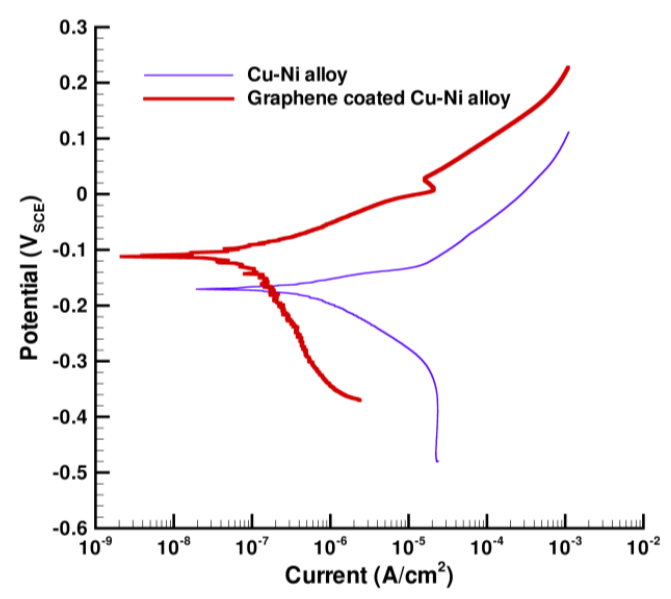

Figure 3. Potentiodynamic polarisation curve for graphene-coated and uncoated Cu-Ni alloy in $0.1 \mathrm{M} \mathrm{NaCl}$.

The diameter of the semicircle of a Nyquist plot and the magnitude of impedance at the lowest frequency in a Bode impedance plot are broad measures of the corrosion resistance. The Bode and Nyquist plots of graphene-coated and uncoated $\mathrm{Cu}-\mathrm{Ni}$ alloy (Figures 4 and 5) demonstrate the corrosion resistance of the graphene-coated $\mathrm{Cu}-\mathrm{Ni}$ alloy to be an order of magnitude greater than that of the bare $\mathrm{Cu}-\mathrm{Ni}$ alloy. It has been argued that multilayer graphene can provide durable corrosion resistance [31]. Accordingly, the considerable improvement in corrosion resistance of graphene-coated Cu-Ni alloy (Figures 4 and 5) is attributed to the multilayer graphene (as established by the Raman spectrum in Figure 1). The Bode phase plots for graphene-coated and uncoated $\mathrm{Cu}-\mathrm{Ni}$ alloys during a $1 \mathrm{~h}$ immersion in $0.1 \mathrm{M} \mathrm{NaCl}$ solution are presented in Figure 6. The broad phase angle peaks in the Bode phase plots suggest a merger of two time constants in each case. The two time constants are attributed to the coating/solution interface and the metal/solution interface in the case of the graphene-coated $\mathrm{Cu}-\mathrm{Ni}$ alloy, whereas they are ascribed to corrosion products/solution interface and metal/solution interface in the case of the bare $\mathrm{Cu}-\mathrm{Ni}$ alloy [10].

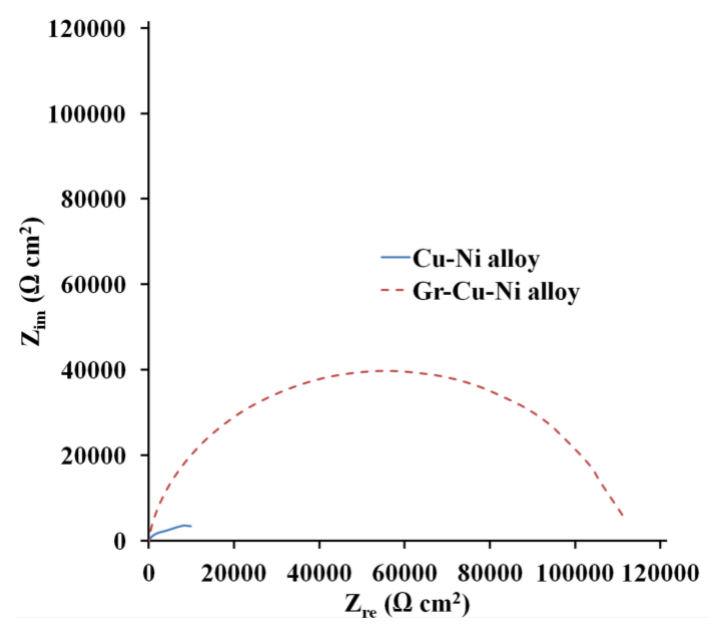

Figure 4. Nyquist plots showing the corrosion resistance of bare and graphene-coated Cu-Ni alloy in $0.1 \mathrm{M} \mathrm{NaCl}$. 
It is important to note that graphene in the study of Singh Raman et al. [10] was mono- to bi-layer, as compared to the few layers of graphene in this study (as confirmed by the Raman spectrum in Figure 1). A comparison of the polarization and EIS data in Figures 3-5 and those in the study of Singh Raman et al. [10] would suggest the corrosion resistance achieved in the two studies was comparable, in spite of the considerable defects in the coating in this study (Figure 1). The considerable corrosion resistance due to graphene coating in this study is attributed to the multilayer graphene.

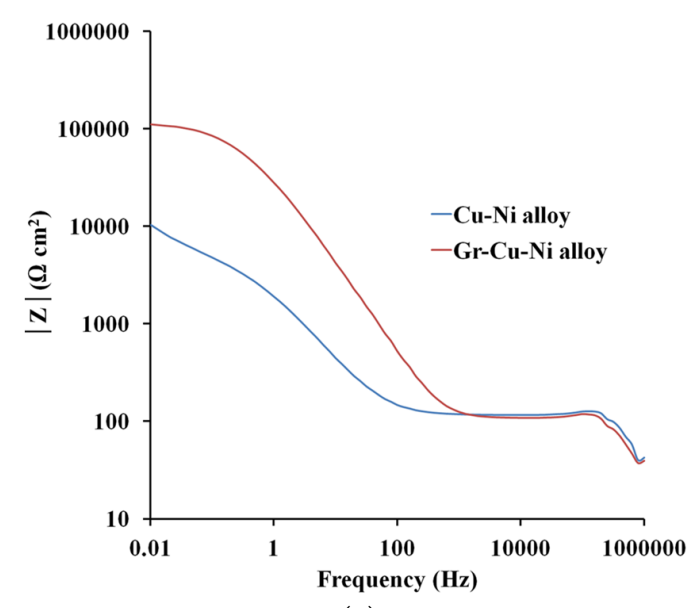

(a)

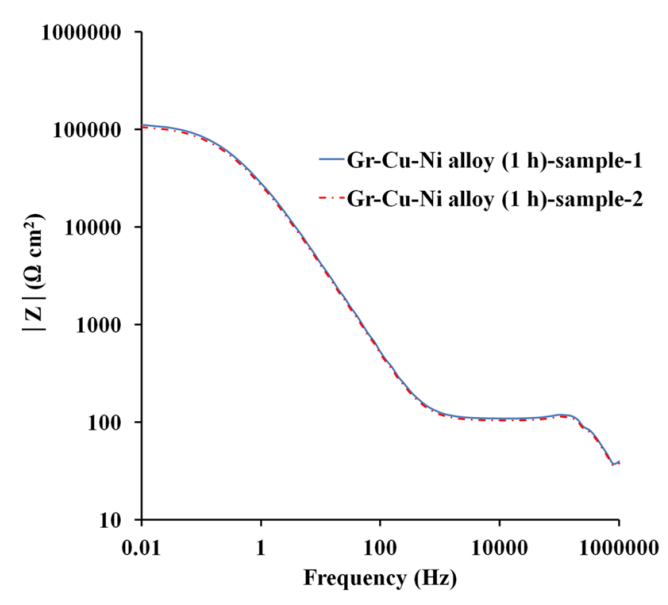

(b)

Figure 5. Bode plots: (a) for bare and graphene-coated $\mathrm{Cu}-\mathrm{Ni}$ alloy ( $\mathrm{Gr}-\mathrm{Cu}-\mathrm{Ni})$; and (b) duplicate plots for graphene-coated $\mathrm{Cu}-\mathrm{Ni}$ alloy showing reproducibility, in $0.1 \mathrm{M} \mathrm{NaCl}$.

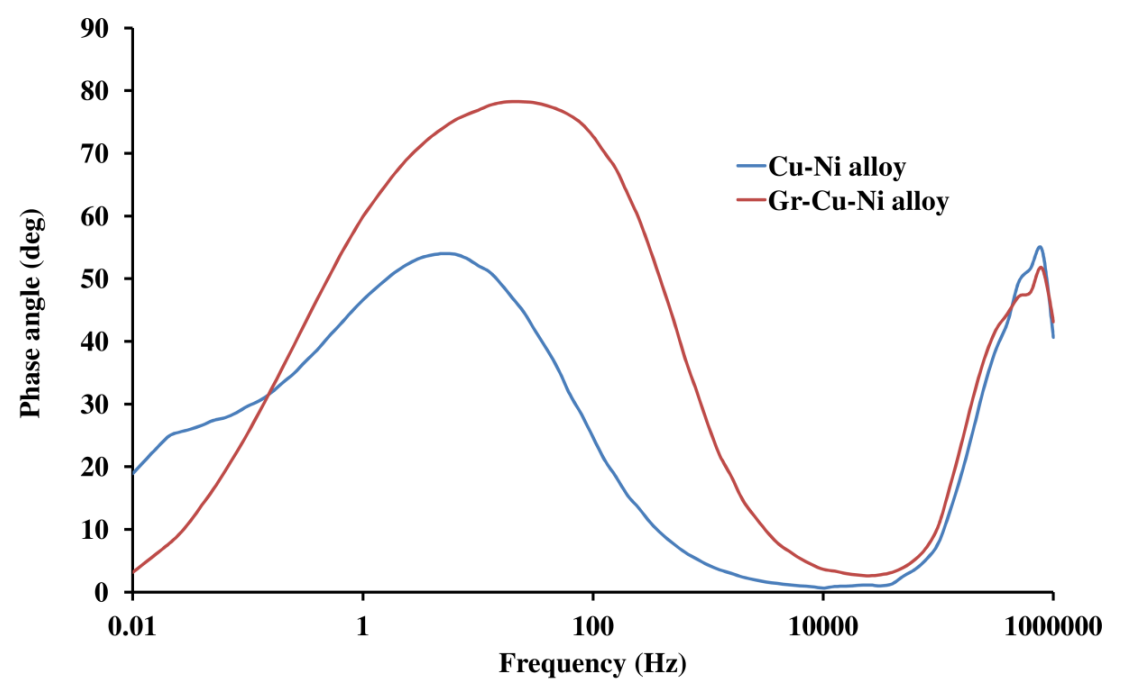

Figure 6. Bode phase angle plots for bare and graphene-coated $\mathrm{Cu}-\mathrm{Ni}$ alloy $(\mathrm{Gr}-\mathrm{Cu}-\mathrm{Ni})$ in $0.1 \mathrm{M} \mathrm{NaCl}$.

\subsection{Durable Corrosion Resistance due to Graphene Coating}

It is still of great technical importance to investigate whether the corrosion resistance due to graphene coating after $1 \mathrm{~h}$ of immersion in $0.1 \mathrm{M} \mathrm{NaCl}$ solution could be sustained for longer durations. Thus, an EIS study was carried out in $0.1 \mathrm{M} \mathrm{NaCl}$ after an extended period of immersion $(24,48,216$, $336 \mathrm{~h}$ ) in $0.1 \mathrm{M} \mathrm{NaCl}$. The Bode impedance plots in Figure 7 demonstrate the improvement in corrosion resistance (i.e., impedance at the lowest frequency) due to graphene coating by an order of magnitude after $1 \mathrm{~h}$ of immersion in $0.1 \mathrm{M} \mathrm{NaCl}$ to be maintained even after a long immersion period of $336 \mathrm{~h}$. As shown in Figure $7 \mathrm{~b}-\mathrm{e}$, the impedance spectra are quite reproducible. 


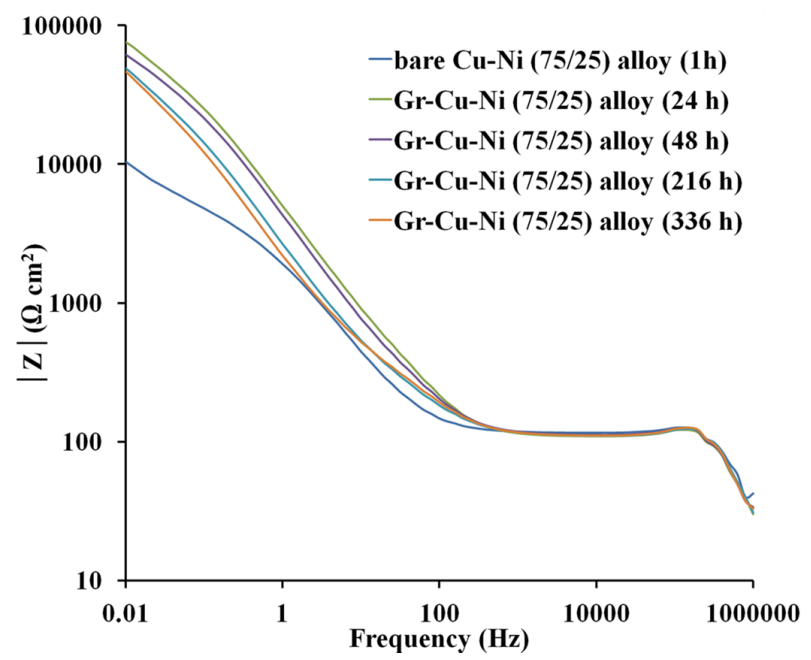

(a)

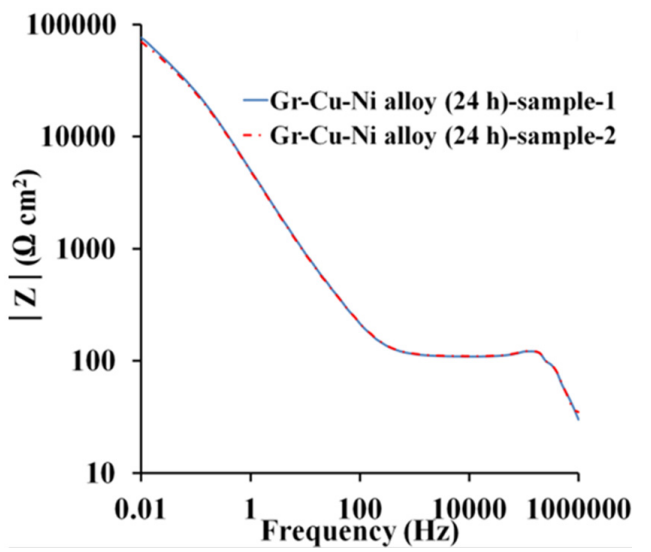

(b)

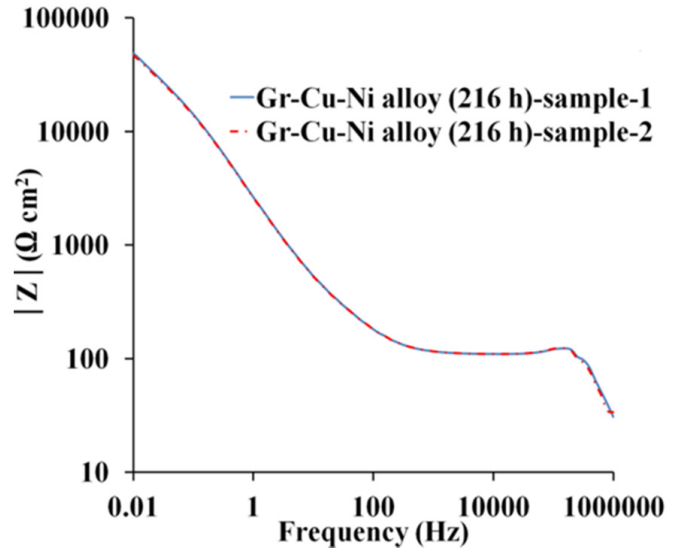

(d)

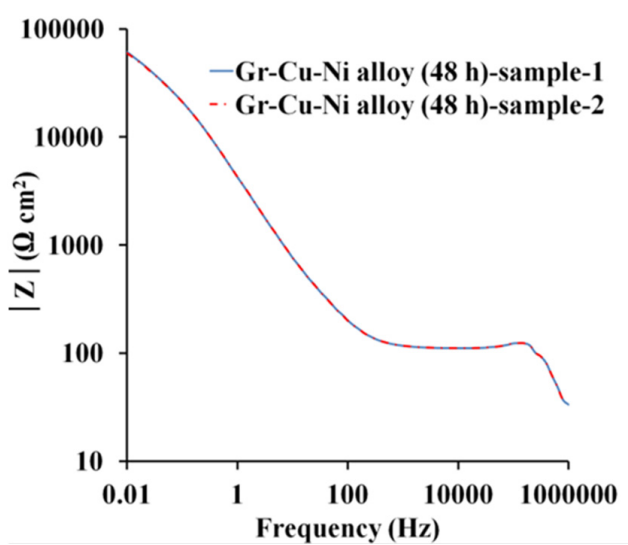

(c)

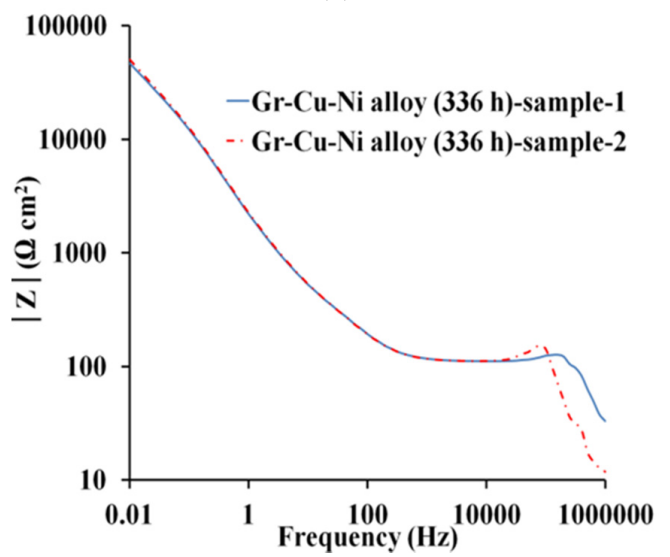

(e)

Figure 7. (a) Bode modulus plots for bare $\mathrm{Cu}-\mathrm{Ni}$ alloy and graphene-coated $\mathrm{Cu}-\mathrm{Ni}$ alloy (Gr-Cu-Ni) in $0.1 \mathrm{M} \mathrm{NaCl}$ (Note: the bare Cu-Ni alloy was only immersed for $1 \mathrm{~h}$ ); and (b-e) Bode modulus plots showing the reproducibility of data after immersion for (b) $24 \mathrm{~h}$, (c) $48 \mathrm{~h}$, (d) $216 \mathrm{~h}$, and (e) $336 \mathrm{~h}$.

The broad phase angle peaks in Bode phase plots after different durations of immersion are attributed to two time constants in each case (Figure 8). As described earlier, the two time constants are ascribed to the presence of the two interfaces, i.e., the graphene coating/solution interface and the metal/solution interface in the case of the graphene-coated $\mathrm{Cu}-\mathrm{Ni}$ alloy, while the two time constants are due to the development of metal hydroxide/oxide films, i.e., corrosion products/solution 
interface and metal/solution interface in the case of the bare $\mathrm{Cu}-\mathrm{Ni}$ alloy. The Bode phase plots after different immersion times have a similar magnitude of phase maximum; however, the phase maximum gradually shifts towards a lower frequency with increasing immersion periods, which is attributed to the increase in the amount of corrosion products over time. The constant nature of the Nyquist and Bode plots for the graphene-coated $\mathrm{Cu}-\mathrm{Ni}$ alloy through the entire period of immersion, 1-336 $\mathrm{h}$ (Figures 7 and 8), and the reproducibility of the data confirmed the ability of a multilayer graphene coating to provide corrosion resistance in the long term.

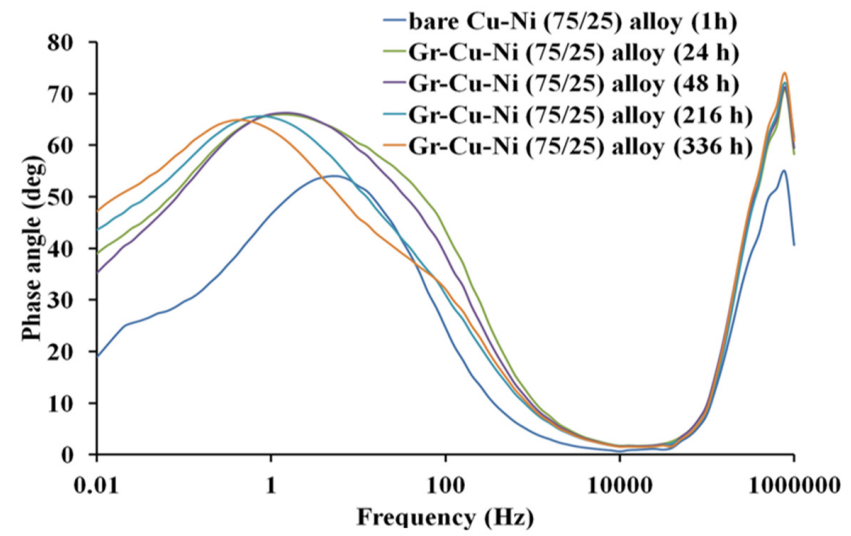

(a)

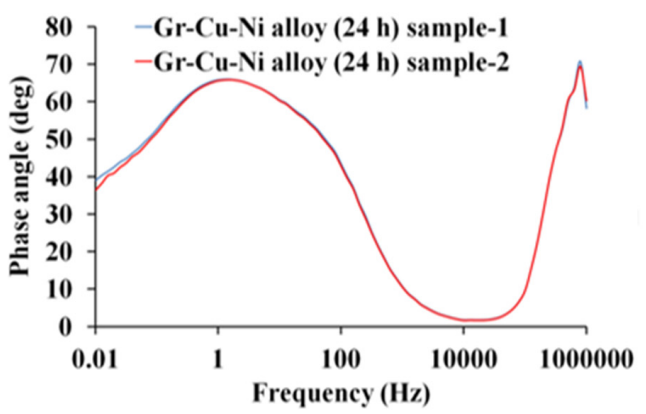

(b)

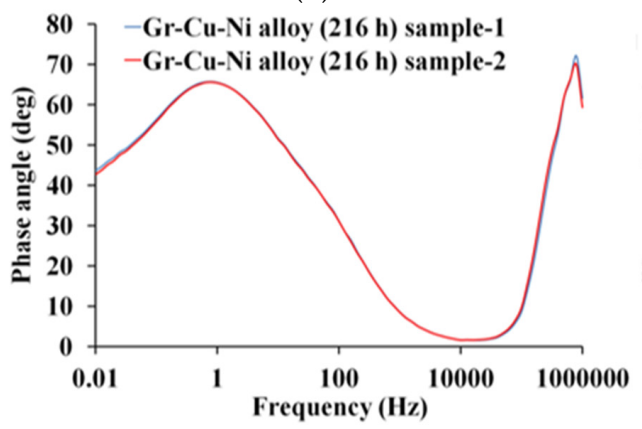

(d)

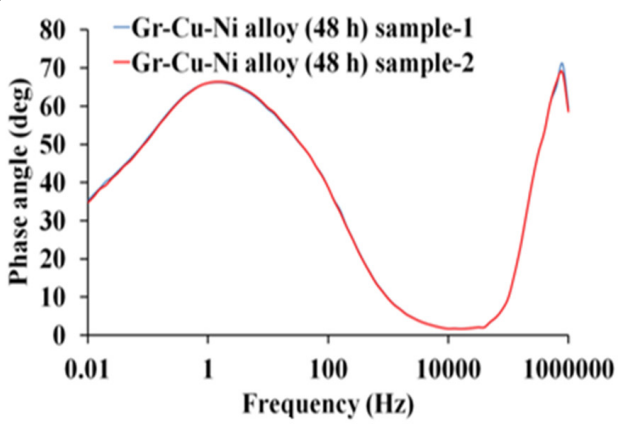

(c)

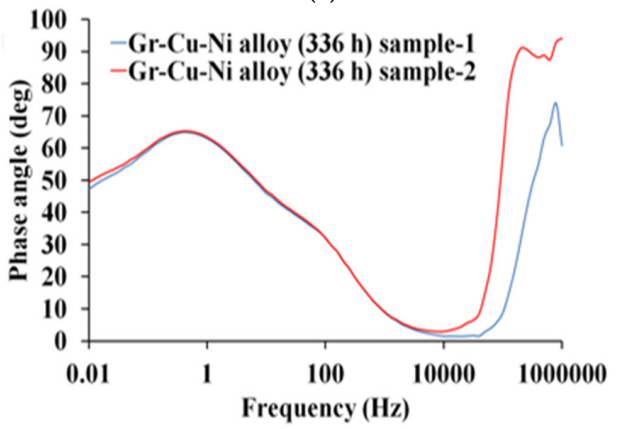

(e)

Figure 8. (a) Bode phase plots for bare and graphene-coated $\mathrm{Cu}-\mathrm{Ni}$ alloy ( $\mathrm{Gr}-\mathrm{Cu}-\mathrm{Ni}$ ) in $0.1 \mathrm{M} \mathrm{NaCl}$ (Note: the bare $\mathrm{Cu}-\mathrm{Ni}$ alloy was only immersed for $1 \mathrm{~h}$ ); and (b-e) Bode modulus plots showing the reproducibility of data after immersion for (b) $24 \mathrm{~h}$, (c) $48 \mathrm{~h}$, (d) $216 \mathrm{~h}$, and (e) $336 \mathrm{~h}$.

Simulation of experimental EIS data was carried out to quantitatively determine the characteristic parameters like capacitance, charge transfer resistance, pore resistance, etc. using a proper equivalent electrical circuit (EEC), taking into account a speculative corrosion mechanism. An EEC with two time constants is shown in Figure 9. There are two time constants: one in the high-frequency region corresponds to the graphene coating/solution and another in a lower-frequency region corresponds to the metal/solution interface. 


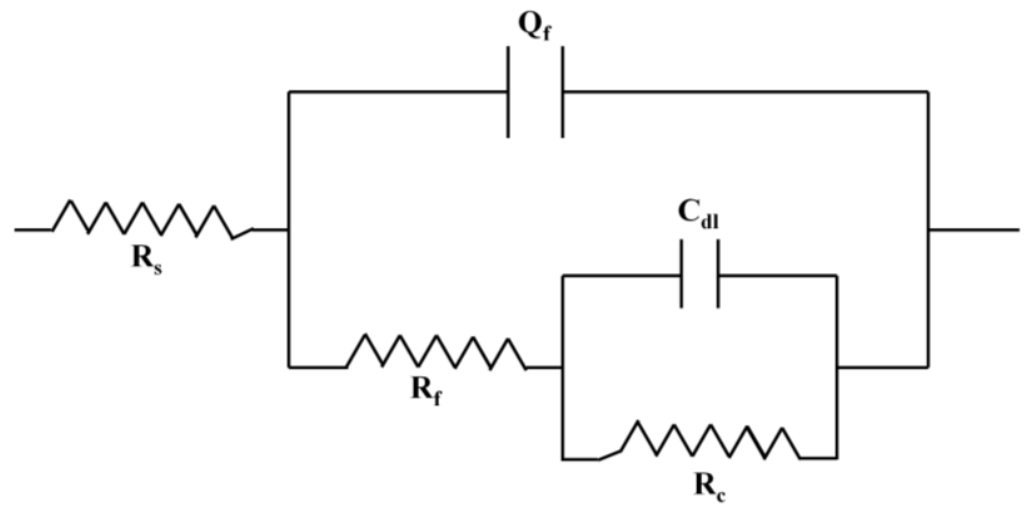

Figure 9. Equivalent electrical circuit (EEC) for corrosion of bare and graphene-coated Cu-Ni alloy.

The EEC shown in Figure 9 was picked as a result of the interconnected nature of the coating defects (for example: graphene grain boundaries for graphene-coated $\mathrm{Cu}-\mathrm{Ni}$ alloy or oxide/hydroxide porosity for bare $\mathrm{Cu}-\mathrm{Ni}$ alloy). In the EEC, $R_{s}$ is the solution resistance, $Q_{f}$ and $R_{f}$ represent the constant phase element (CPE) and the film resistance in parallel combination to represent graphene coating, respectively, $C_{d l}$ is the electrical double layer capacitance, and $R_{c}$ is the charge transfer resistance. The CPE conduct is by and large credited to the distributed surface reactivity, roughness, and electrode porosity [30,32]. The PAR ZSimp package for Windows was used for impedance investigation between frequencies 10,000 Hz and $0.1 \mathrm{~Hz}$. The characteristic EEC parameters are presented in Table 3.

Table 3. Quantitative analysis of EIS data using model EEC: $R_{S}\left(Q_{f}\left[R_{f}\left(C_{d l} R_{c}\right)\right]\right)$ as in Figure 9.

\begin{tabular}{|c|c|c|c|c|c|c|c|c|}
\hline $\begin{array}{c}\text { Sample, } \\
\text { Immersion } \\
\text { Time }\end{array}$ & $R_{f}\left(\Omega \mathrm{cm}^{2}\right)$ & $R_{c}\left(\Omega \mathrm{cm}^{2}\right)$ & $Q_{f}\left(\mathrm{~F} / \mathrm{cm}^{2}\right)$ & $n$ & $C_{d l}\left(\mathrm{~F} / \mathrm{cm}^{2}\right)$ & $\begin{array}{c}\text { Chi Squared } \\
\text { Value }\end{array}$ & $\begin{array}{c}\text { Total } \\
\text { Error } \\
(\%)\end{array}$ & $\begin{array}{c}\text { Corrosion } \\
\text { Resistance } \\
\left(R_{f}+R_{c}\right)\left(\Omega \mathrm{cm}^{2}\right)\end{array}$ \\
\hline Bare $\mathrm{Cu}-\mathrm{Ni}, 1 \mathrm{~h}$ & $4.806 \times 10^{3}$ & $3.620 \times 10^{3}$ & $1.002 \times 10^{-4}$ & 0.7796 & $7.202 \times 10^{-4}$ & $8.626 \times 10^{-4}$ & 2.937 & $8.426 \times 10^{3}$ \\
\hline Gr-Cu-Ni, 1 h & $5.957 \times 10^{4}$ & $4.274 \times 10^{4}$ & $4.972 \times 10^{-6}$ & 0.93 & $1.453 \times 10^{-5}$ & $1.362 \times 10^{-3}$ & 3.69 & $10.231 \times 10^{4}$ \\
\hline Gr-Cu-Ni, 24 h & $1.145 \times 10^{4}$ & $6.277 \times 10^{4}$ & $4.387 \times 10^{-5}$ & 0.7743 & $3.308 \times 10^{-6}$ & $5.929 \times 10^{-4}$ & 2.435 & $7.422 \times 10^{4}$ \\
\hline Gr-Cu-Ni, 48 h & $4.749 \times 10^{3}$ & $5.677 \times 10^{4}$ & $5.128 \times 10^{-5}$ & 0.7712 & $3.407 \times 10^{-6}$ & $2.102 \times 10^{-4}$ & 1.45 & $6.152 \times 10^{4}$ \\
\hline Gr-Cu-Ni, 216 h & $1.720 \times 10^{3}$ & $6.57 \times 10^{4}$ & $8.097 \times 10^{-5}$ & 0.7364 & $1.036 \times 10^{-5}$ & $1.461 \times 10^{-4}$ & 1.209 & $6.742 \times 10^{4}$ \\
\hline Gr-Cu-Ni, 336 h & $1.742 \times 10^{3}$ & $1.01 \times 10^{5}$ & $9.388 \times 10^{-5}$ & 0.7009 & $1.908 \times 10^{-5}$ & $5.357 \times 10^{-4}$ & 2.314 & $10.274 \times 10^{4}$ \\
\hline
\end{tabular}

Table 3 reveals that the corrosion resistance of multilayer graphene-coated $\mathrm{Cu}-\mathrm{Ni}$ alloy, an aggregate of pore resistance and the resistance offered by the interface of multilayer graphene and electrolyte $\left(R_{c}\right)$, is $10.231 \times 10^{4} \Omega \mathrm{cm}^{2}, 7.422 \times 10^{4} \Omega \mathrm{cm}^{2}, 6.152 \times 10^{4} \Omega \mathrm{cm}^{2}, 6.742 \times 10^{4} \Omega \mathrm{cm}^{2}$, and $10.274 \times 10^{4} \Omega \mathrm{cm}^{2}$ for the immersion periods of $1,24,48,216$, and $336 \mathrm{~h}$, respectively and that of the uncoated/bare Cu-Ni alloy is $8.426 \times 10^{3} \Omega \mathrm{cm}^{2}$ (for the bare Cu-Ni alloy, it is the sum of pore resistance and the resistance offered by the metal/electrolyte interface).

The data in Table 3 confirm that multilayer graphene coating improves corrosion resistance of a Cu-Ni alloy by an order of magnitude and this improvement in corrosion resistance is sustained for long periods of immersion ( $336 \mathrm{~h}$ ), which is consistent with the Bode plots in Figure 5. The lower $Q_{f}$ of multilayer graphene indicates a lower number of conductive pathways in multilayer graphene coating and the relatively lower $C_{d l}$ of multilayer graphene coating demonstrates the lower exposure of the metal/electrolyte interface. The exponent of CPE is close to 1, showing the almost completely capacitative nature of graphene coating. The low chi-squared value indicates the reasonable accuracy of EEC parameters obtained by EIS data simulation. Figure 10a-c demonstrates the fitting of simulated EIS data with the experimental EIS data of a graphene-coated $\mathrm{Cu}-\mathrm{Ni}$ alloy for immersion periods of $1 \mathrm{~h}, 48 \mathrm{~h}$, and $336 \mathrm{~h}$, respectively. The experimental data match well with the simulated data in the frequency range from 10,000 Hz to $0.1 \mathrm{~Hz}$, as is evident from Figure 10. The total error in the impedance analysis in the simulation of experimental data when utilizing EEC (Figure 9) was under 4\% 
in all simulations. The low associated chi-squared values and low total error confirm the legitimacy of the utilised EEC (Figure 9) and corrosion mechanism for graphene-coated and uncoated $\mathrm{Cu}$-Ni alloys.

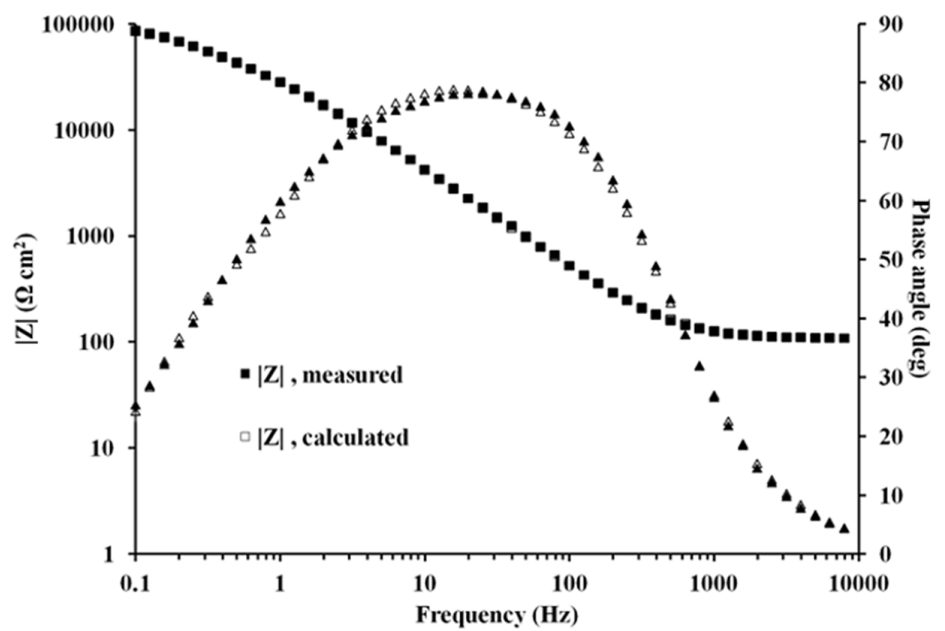

(a)

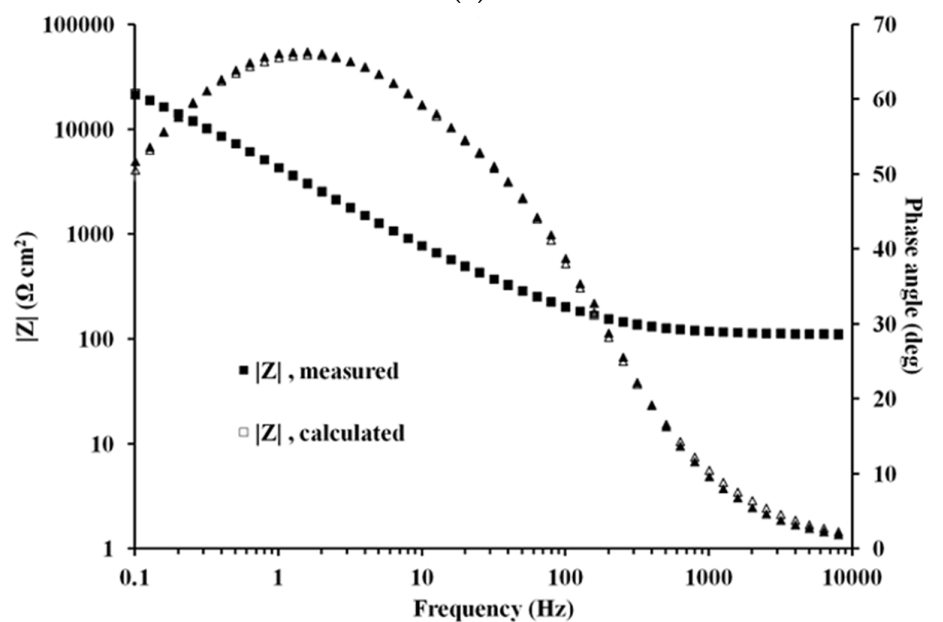

(b)

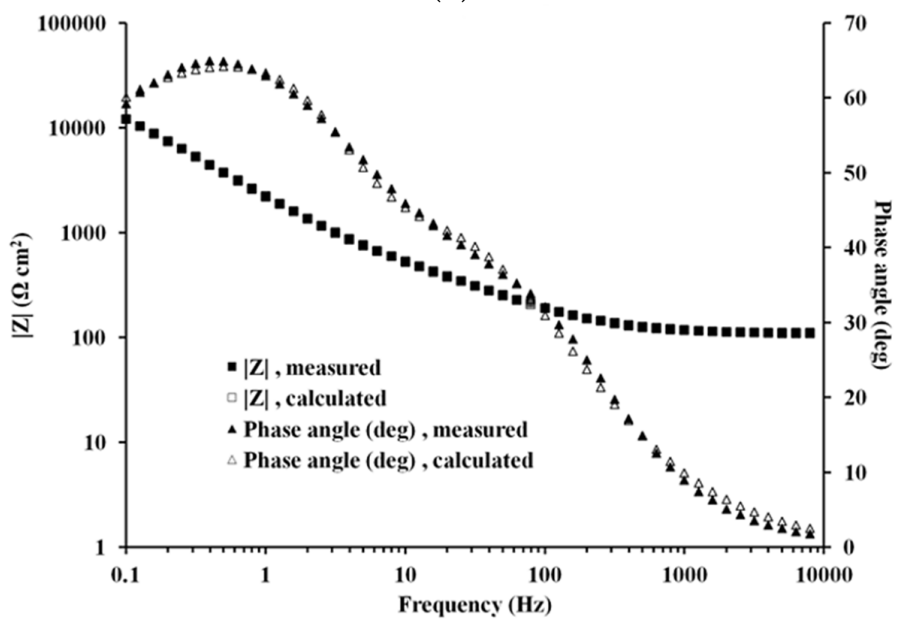

(c)

Figure 10. Curve fitting of experimental and simulated Bode plots for graphene-coated Cu-Ni alloy after immersion in $0.1 \mathrm{M} \mathrm{NaCl}$ for (a) $1 \mathrm{~h}$, (b) $48 \mathrm{~h}$, and (c) $336 \mathrm{~h}$. 


\section{Conclusions}

Graphene coating was successfully synthesized on a $\mathrm{Cu}-\mathrm{Ni}$ alloy using the chemical vapour deposition technique. Electrochemical tests indicated that the multilayer graphene coating acted as a considerable corrosion barrier for the $\mathrm{Cu}-\mathrm{Ni}$ alloy and provided a durable corrosion protection in $0.1 \mathrm{M} \mathrm{NaCl}$. The corrosion resistance conferred by the multilayer graphene coating on $\mathrm{Cu}-\mathrm{Ni}$ alloy was sustained for an extended duration (up to $336 \mathrm{~h}$ ). In this context, it is important to note that the graphene coating has been reported to provide insignificant improvement in corrosion in a few studies. In fact, some reports have suggested a deterioration in corrosion resistance due to graphene coating. Such contradictory findings, as reported in the literature, could be addressed thoroughly through the findings of this study. The inferior or insignificant corrosion resistance due to graphene coating is attributed to the poor quality of graphene (to be precise, the extent of surface coverage and the defect content of the graphene coating). The suggestion in the present study that multilayer graphene (instead of single layer graphene) can provide a superior surface coverage and durable corrosion resistance to the $\mathrm{Cu}-\mathrm{Ni}$ alloy was found to be valid. The reason for superior corrosion resistance with multilayer graphene is that the pores/defects in single-layer graphene that were responsible for the deterioration in corrosion resistance could be blocked by the subsequent over-layer, thereby improving the corrosion resistance.

Supplementary Materials: The following are available online at http:/ / www.mdpi.com/2079-6412/7/12/210/s1. Figure S1. (a) Raman spectrum of solid silicon standard showing Raman peak at $520.5 \mathrm{~cm}^{-1}$, which indicates that the Raman system is wavenumber-calibrated; (b) optical micrograph of solid silicon; and (c) optical micrograph of laser spot; Figure S2. Raman spectrum of a graphene-coated Cu-Ni alloy at different spots showing the uniformity of graphene over the sample surface.

Acknowledgments: The authors would like to thank Department of Mechanical Engineering, Monash University, Australia. Abhishek Tiwari would like to acknowledge Monash Departmental Scholarship for funding his living expenses and tuition fees during his Ph.D. at Monash University, Australia. Abhishek Tiwari would like to acknowledge Department of Chemistry, Monash University, Australia for providing a facility for Raman spectroscopy.

Author Contributions: Abhishek Tiwari conceived the idea and designed and built the CVD reactor for graphene synthesis, planned and performed the experiments, analysed the experimental data, and wrote the manuscript. R. K. Singh Raman directed and supervised the research and provided help for editing the manuscript and provided useful insights into the manuscript.

Conflicts of Interest: The authors declare no conflict of interest.

\section{References}

1. Jones, D.A. Principles and Prevention of Corrosion, 2nd ed.; Prentice Hall: Upper Saddle River, NJ, USA, 1996.

2. Stolyarova, E.; Stolyarov, D.; Bolotin, K.; Ryu, S.; Liu, L.; Rim, K.T.; Klima, M.; Hybertsen, M.; Pogorelsky, I.; Pavlishin, I.; et al. Observation of graphene bubbles and effective mass transport under graphene films. Nano Lett. 2008, 9, 332-337. [CrossRef] [PubMed]

3. Bunch, J.S.; Verbridge, S.S.; Alden, J.S.; van der Zande, A.M.; Parpia, J.M.; Craighead, H.G.; McEuen, P.L. Impermeable atomic membranes from graphene sheets. Nano Lett. 2008, 8, 2458-2462. [CrossRef] [PubMed]

4. Lee, C.; Wei, X.; Kysar, J.W.; Hone, J. Measurement of the elastic properties and intrinsic strength of monolayer graphene. Science 2008, 321, 385-388. [CrossRef] [PubMed]

5. Politano, A.; Chiarello, G. Probing Young's modulus and Poisson's ratio in graphene/metal interfaces and graphite: A comparative study. Nano Res. 2015, 8, 1847-1856. [CrossRef]

6. Politano, A.; Cattelan, M.; Boukhvalov, D.W.; Campi, D.; Cupolillo, A.; Agnoli, S.; Apostol, N.G.; Lacovig, P.; Lizzit, S.; Farías, D.; et al. Unveiling the mechanisms leading to $\mathrm{H}_{2}$ production promoted by water decomposition on epitaxial graphene at room temperature. ACS Nano 2016, 10, 4543-4549. [CrossRef] [PubMed]

7. Feng, X.; Maier, S.; Salmeron, M. Water splits epitaxial graphene and intercalates. J. Am. Chem. Soc. 2012, 134, 5662-5668. [CrossRef] [PubMed]

8. Politano, A.; Chiarello, G. Graphene on $\mathrm{Pt}_{3} \mathrm{Ni}(111)$ : A suitable platform for tunable charge doping, electron-phonon coupling and plasmonic excitations. 2D Mater. 2017, 4, 035003. [CrossRef] 
9. Gugliuzza, A.; Politano, A.; Drioli, E. The advent of graphene and other two-dimensional materials in membrane science and technology. Curr. Opin. Chem. Eng. 2017, 16, 78-85. [CrossRef]

10. Singh Raman, R.K.; Chakraborty Banerjee, P.; Lobo, D.E.; Gullapalli, H.; Sumandasa, M.; Kumar, A.; Choudhary, L.; Tkacz, R.; Ajayan, P.M.; Majumder, M. Protecting copper from electrochemical degradation by graphene coating. Carbon 2012, 50, 4040-4045. [CrossRef]

11. Chen, S.; Brown, L.; Levendorf, M.; Cai, W.; Ju, S.-Y.; Edgeworth, J.; Li, X.; Magnuson, C.W.; Velamakanni, A.; Piner, R.D.; et al. Oxidation resistance of graphene-coated $\mathrm{Cu}$ and $\mathrm{Cu} / \mathrm{Ni}$ alloy. ACS Nano 2011, 5, 1321-1327. [CrossRef] [PubMed]

12. Prasai, D.; Tuberquia, J.C.; Harl, R.R.; Jennings, G.K.; Bolotin, K.I. Graphene: Corrosion-inhibiting coating. ACS Nano 2012, 6, 1102-1108. [CrossRef] [PubMed]

13. Kirkland, N.T.; Schiller, T.; Medhekar, N.; Birbilis, N. Exploring graphene as a corrosion protection barrier. Corros. Sci. 2012, 56, 1-4. [CrossRef]

14. Schriver, M.; Regan, W.; Gannett, W.J.; Zaniewski, A.M.; Crommie, M.F.; Zettl, A. Graphene as a long-term metal oxidation barrier: Worse than nothing. ACS Nano 2013, 7, 5763-5768. [CrossRef] [PubMed]

15. Zhou, F.; Li, Z.; Shenoy, G.J.; Li, L.; Liu, H. Enhanced room-temperature corrosion of copper in the presence of graphene. ACS Nano 2013, 7, 6939-6947. [CrossRef] [PubMed]

16. Wlasny, I.; Dabrowski, P.; Rogala, M.; Kowalczyk, P.J.; Pasternak, I.; Strupinski, W.; Baranowski, J.M.; Klusek, Z. Role of graphene defects in corrosion of graphene-coated $\mathrm{Cu}(111)$ surface. Appl. Phys. Lett. 2013, 102, 111601-111604. [CrossRef]

17. Kalita, G.; Ayhan, M.E.; Sharma, S.; Shinde, S.M.; Ghimire, D.; Wakita, K.; Umeno, M.; Tanemura, M. Low temperature deposited graphene by surface wave plasma CVD as effective oxidation resistive barrier. Corros. Sci. 2014, 78, 183-187. [CrossRef]

18. Hsieh, Y.-P.; Hofmann, M.; Chang, K.-W.; Jhu, J.G.; Li, Y.-Y.; Chen, K.Y.; Yang, C.C.; Chang, W.-S.; Chen, L.-C. Complete corrosion inhibition through graphene defect passivation. ACS Nano 2013, 8, 443-448. [CrossRef] [PubMed]

19. Sakiewicz, P.; Nowosielski, R.; Babilas, R. Production aspects of inhomogeneous hot deformation in as-cast CuNi25 alloy. Indian J. Eng. Mater. Sci. 2015, 22, 389-398.

20. Gudas, J.P.; Hack, H.P. Sulfide induced corrosion of copper nickel alloys. Corrosion 1979, 35, 67-73. [CrossRef]

21. Eiselstein, L.; Caligiuri, R.; Wing, S.; Syrett, B. Mechanisms of Corrosion of Copper-Nickel Alloys in Sulfide-Polluted Seawater; SRI International: Menlo Park, CA, USA, 1981.

22. North, R.F.; Pryor, M.J. The influence of corrosion product structure on the corrosion rate of Cu-Ni alloys. Corros. Sci. 1970, 10, 297-311. [CrossRef]

23. Uhlig, H.H. Passivity in Copper-Nickel and Molybdenum-Nickel-Iron alloys. Trans. Electrochem. Soc. 1944, 85, 307-333. [CrossRef]

24. ASTM F2129-04 Standard Test Method for Conducting Cyclic Potentiodynamic Polarisation Measurements to Determine the Corrosion Susceptibility of Small Implant Devices; ASTM International: West Conshohocken, PA, USA, 2004.

25. Ferrari, A.C.; Meyer, J.C.; Scardaci, V.; Casiraghi, C.; Lazzeri, M.; Mauri, F.; Piscanec, S.; Jiang, D.; Novoselov, K.S.; Roth, S.; et al. Raman spectrum of graphene and graphene layers. Phys. Rev. Lett. 2006, 97 , 187401. [CrossRef] [PubMed]

26. Ni, Z.H.; Wang, H.M.; Kasim, J.; Fan, H.M.; Yu, T.; Wu, Y.H.; Feng, Y.P.; Shen, Z.X. Graphene thickness determination using reflection and contrast spectroscopy. Nano Lett. 2007, 7, 2758-2763. [CrossRef] [PubMed]

27. Reina, A.; Jia, X.; Ho, J.; Nezich, D.; Son, H.; Bulovic, V.; Dresselhaus, M.S.; Kong, J. Large area, few-layer graphene films on arbitrary substrates by chemical vapor deposition. Nano Lett. 2008, 9, 30-35. [CrossRef] [PubMed]

28. John, R.; Ashokreddy, A.; Vijayan, C.; Pradeep, T. Single- and few-layer graphene growth on stainless steel substrates by direct thermal chemical vapor deposition. Nanotechnology 2011, 22, 165701. [CrossRef] [PubMed]

29. Kairy, S.K.; Rometsch, P.A.; Diao, K.; Nie, J.F.; Davies, C.H.J.; Birbilis, N. Exploring the electrochemistry of 6xxx series aluminium alloys as a function of $\mathrm{Si}$ to $\mathrm{Mg}$ ratio, $\mathrm{Cu}$ content, ageing conditions and microstructure. Electrochim. Acta 2016, 190, 92-103. [CrossRef]

30. Barsoukov, E.; Macdonald, J.R. Impedence Spectroscopy: Theory, Experiment, and Applications, 2nd ed.; John Wiley \& Sons, Inc.: Hobokon, NJ, USA, 2005. 
31. Singh Raman, R.K.; Tiwari, A. Graphene: The Thinnest Known Coating for Corrosion Protection. JOM 2014, 66, 637-642. [CrossRef]

32. Chakraborty Banerjee, P.; Singh Raman, R.K. Electrochemical impedance spectroscopic investigation of the role of alkaline pre-treatment in corrosion resistance of a silane coating on magnesium alloy, ZE41. Electrochim. Acta 2011, 56, 3790-3798. [CrossRef] 